NBER WORKING PAPER SERIES

\title{
A NOTE ON LIQUIDITY RISK MANAGEMENT
}

\author{
Markus K. Brunnermeier \\ Motohiro Yogo \\ Working Paper 14727 \\ http://www.nber.org/papers/w14727
NATIONAL BUREAU OF ECONOMIC RESEARCH
1050 Massachusetts Avenue
Cambridge, MA 02138
February 2009

For comments and discussions, we thank Patrick Cheridito, Nicolae Gârleanu, Leonid Kogan, Arvind Krishnamurthy, Guido Lorenzoni, Martin Oehmke, Lasse Pederesen, Martin Schmalz, Hyun Shin, Wei Xiong, and participants of the AEA session on "Liquidity, Macroeconomics, and Asset Prices". The views expressed herein are those of the author(s) and do not necessarily reflect the views of the National Bureau of Economic Research.

NBER working papers are circulated for discussion and comment purposes. They have not been peerreviewed or been subject to the review by the NBER Board of Directors that accompanies official NBER publications.

(C) 2009 by Markus K. Brunnermeier and Motohiro Yogo. All rights reserved. Short sections of text, not to exceed two paragraphs, may be quoted without explicit permission provided that full credit, including (C) notice, is given to the source. 
A Note on Liquidity Risk Management

Markus K. Brunnermeier and Motohiro Yogo

NBER Working Paper No. 14727

February 2009, Revised August 2009

JEL No. G32,G33

\begin{abstract}
$\underline{\text { ABSTRACT }}$
When a firm is unable to roll over its debt, it may have to seek more expensive sources of financing or even liquidate its assets. This paper provides a normative analysis of minimizing such rollover risk, through the optimal dynamic choice of the maturity structure of debt. The objective of a firm with long-term assets is to maximize the effective maturity of its liabilities across several refinancing cycles, rather than to maximize the maturity of the current bonds outstanding. An advantage of short-term financing is that a firm, while in good financial health, can readjust its maturity structure more quickly in response to changes in its asset value.
\end{abstract}

Markus K. Brunnermeier

Princeton University

Department of Economics

Bendheim Center for Finance

Princeton, NJ 08540

and NBER

markus@princeton.edu

Motohiro Yogo

University of Pennsylvania

The Wharton School

Finance Department

3620 Locust Walk

Philadelphia, PA 19104-6367

and NBER

yogo@wharton.upenn.edu 
We study a simple model of liquidity risk management in which a firm is subject to rollover risk. When a firm is unable to roll over its maturing bonds by issuing new bonds, it may have to seek more expensive sources of financing or even liquidate its assets, possibly at fire-sale prices. One way to reduce this risk is to hold excess cash reserves, which can be expensive in practice (Bengt Holmström and Jean Tirole 2000; 2001). In this paper, we focus on an alternative way of managing liquidity risk, through the optimal dynamic choice of the maturity structure of debt.

Our analysis highlights one advantage of short-term financing. The firm, while in good financial health, can readjust its maturity structure more quickly in response to changes in its asset value. Ideally, the firm would secure long-term financing just prior to when its financial health may worsen. Through this strategy, the firm can secure financing for the longest continuous period possible without rollover failure, avoiding inefficient restructuring costs. Put differently, the objective of the firm with long-term assets is to maximize the effective maturity of its liabilities across several refinancing cycles, rather than to maximize the maturity of the current bonds outstanding.

Our analysis adds a new dimension to interest-rate risk management (or duration hedging), which is the traditional method of choosing the maturity structure of debt (Oldrich Vasicek 1977). Duration hedging shields the firm's net worth from (at least small) changes in interest rates, by matching the interest-rate sensitivity of its liabilities to that of its assets. In reality, the firm's long-term assets are also exposed to sources of risk other than changes in interest rates. These sources of risk can cause rollover failure that are not hedged by interest-rate risk management. Our paper provides a normative analysis of liquidity risk hedging that goes beyond traditional duration hedging. It prescribes the optimal maturity of debt for a single firm, taking the supply of credit as exogenously given. Importantly, we abstract from the role of informational frictions that lead to signalling of credit quality, which limits the maturity of bonds available to the firm (Mark J. Flannery 1986; Douglas W. Diamond 1991). The firm's maturity choice can also be limited due to a rat race among 
creditors to shorter and shorter maturity (Markus K. Brunnermeier and Martin Oehmke 2009).

In Section I, we first illustrate our main point with a simple three-period example. We develop a more general model of liquidity risk management in Section II. We discuss additional issues that are outside the scope of our main analysis in Section III.

\section{Three-Period Example of Liquidity Risk Manage- ment}

We start with a simple three-period example, which captures the essential insights of the paper. In order to highlight the differences from interest-rate risk management, we assume that the riskless interest rate at all maturities is constant and equal to zero.



Figure 1: Present Value of the Project's Payoff in Period 3

Consider a long-term project that costs $\$ 100$ in period 0 . The project matures in period 3 and has payoffs given by the binomial model in Figure 1. Prior to maturity, information about the value of the project is revealed through the binomial model. The probability of an up/down movement is 0.5 at each node. The present value of the terminal payoff is $\$ 103$ in period 0 , and it changes in increments of $\pm \$ 2$ from one period to the next.

The owner of the project, or the firm, has no initial capital. Unspecified incentive constraints prevent the firm from issuing equity. The ability to issue three-period bonds would solve the financing problem trivially. Therefore, we assume that the firm can only issue zero- 
coupon bonds of one- or two-period maturity. For simplicity, the firm can finance itself with bonds of one type of maturity in any given period, and bonds cannot be repurchased prior to maturity. For a discussion of financing with multiple maturities and repurchases, we refer the reader to Section III. All bonds are held by a continuum of small, risk-neutral bondholders of measure one, who can also invest in a riskless asset. Consequently, bondholders never accept investment opportunities with negative expected returns.

If the firm cannot roll over its maturing bonds in any period prior to period 3 , it must go through debt restructuring. We assume that debt restructuring reduces the overall value of the project by $\$ 16$. In practice, debt restructuring can be costly for three main reasons. First, a distinctive feature of bonds, in contrast to loans, is that owners of bonds are dispersed and typically difficult to locate. This makes renegotiation difficult and potentially costly (e.g., see Lee C. Buchheit and G. Mitu Gulati 2002). Second, the firm may have to resort to more expensive sources of financing subsequent to rollover failure. Finally, the firm may be forced to liquidate the project at a fire-sale price in extreme circumstances. In the terminology of Markus K. Brunnermeier and Lasse Heje Pedersen (2009), the project's low market liquidity increases rollover risk, which is a type of funding illiquidity.

In period 0 , consider two different financing strategies. In a "long-short" strategy, the firm initially issues two-period bonds, and then rolls them over as one-period bonds from period 2 to 3 . In a "short-long" strategy, the firm initially issues one-period bonds, and then rolls them over as two-period bonds from period 1 to 3 . Conventional interest-rate risk management does not give us clear guidance on the optimal financing strategy as both strategies use the same bonds, only in a different order. We now show that the short-long strategy dominates the long-short strategy from the perspective of liquidity risk management. In fact, the short-long strategy is the only way in which the firm can successfully finance the project in this simple example.

Following the long-short strategy, suppose the two-period bond matures at node (2c), where the present value of the project is only $\$ 99$. A debt-overhang problem (Stewart C. 
Myers 1977) prevents the firm from raising more than $\$ 99$ at node (2c). Because the firm cannot roll over its maturing bonds whose face value is at least $\$ 100$, the firm has to go through costly debt restructuring, which reduces the firm value to $\$ 99-\$ 16=\$ 83$ at node (2c). In period 0 , the present value of the firm is therefore no more than $0.25 \times \$ 107+0.5 \times$ $\$ 103+0.25 \times \$ 83=\$ 99$. Therefore, the firm is unable to raise the $\$ 100$ necessary to start the project. ${ }^{1}$

In contrast, the short-long strategy leads to successful financing until the project's maturity. Suppose the one-period bond matures at node (1b), where the present value of the project is $\$ 101$. The firm can then issue two-period bonds worth $\$ 100$, which ensures financing until the project's maturity. These two-period bonds sell at a discount relative to their face value of $\$ 101$, in order to compensate the bondholders for the possibility of default at node (3d). In period 0, the present value to the bondholders is $\$ 100$, and the firm's net worth is $\$ 3$.

\section{A Model of Liquidity Risk Management}

We now show that the insights of the three-period example extend to an infinite-horizon binomial model. Our model is a normative model of liquidity risk management in the spirit of textbook models of interest-rate risk management. Through our model, we are able to give some guidance on the optimal maturity structure of bonds that minimizes rollover risk.

Time is discrete and indexed by $t$. The continuously compounded riskless interest rate at all maturities is constant and equal to $r$. There is an infinitely lived project whose discounted value is a martingale,

$$
X_{t}=\mathbf{E}_{t}\left[e^{-r} X_{t+1}\right] .
$$

\footnotetext{
${ }^{1}$ Note that the long-short strategy is inefficient even if the debt restructuring cost were significantly lower than $\$ 16$. With a smaller cost, the firm can start the project in period 0 , but it will be unable to roll over its bonds at node $(2 \mathrm{c})$.
} 
The value of the project is governed by a geometric binomial process, where the increments $X_{t+1} / X_{t}$ are independently and identically distributed. The project matures at a random time $T$, after which the entire value of the project $X_{T}$ becomes pledgable. The distribution of $T$ is geometric and independent of the value of the project. We use $\operatorname{Pr}(m)=\operatorname{Pr}(T>$ $t+m \mid T>t)$ to simplify notation.

A firm must finance the project through zero-coupon bonds of maturity up to $M$. We continue to assume that the firm can only issue one type of maturity in any given period, and that bonds cannot be repurchased prior to maturity. In addition, the firm cannot store cash. All bonds are held by a continuum of small risk-neutral bondholders of measure one, whose continuously compounded expected return is $r$.

Suppose the project has not matured through period $t$. In addition, there are outstanding bonds with face value $F_{t}$ which mature in period $t$. Rollover financing is feasible whenever the firm can raise enough funds, through the issuance of new bonds, to repay the full face value of maturing bonds. If the firm fails to roll over its bonds in any period $t<T$ prior to the project's maturity, it must pay a restructuring cost of $\lambda X_{t}$ where $\lambda \in(0,1)$. Let $V_{t}$ be the firm's borrowing capacity in period $t$. The firm can roll over the outstanding bonds if the rollover constraint is satisfied:

$$
V_{t} \geq F_{t}
$$

Suppose the firm were to issue bonds of maturity $m$ with face value $F_{t+m}$ in period $t$. The firm's borrowing capacity under this policy is

$$
\begin{aligned}
V_{t}(m) & =(1-\operatorname{Pr}(m)) \mathbf{E}_{t}\left[e^{-m r} X_{t+m}\right]+\operatorname{Pr}(m) \mathbf{E}_{t}\left[e^{-m r}\left(V_{t+m}-1_{\left\{V_{t+m}<F_{t+m}\right\}} \lambda X_{t+m}\right)\right] \\
& =X_{t}+\operatorname{Pr}(m) \mathbf{E}_{t}\left[e^{-m r}\left(V_{t+m}-X_{t+m}-1_{\left\{V_{t+m}<F_{t+m}\right\}} \lambda X_{t+m}\right)\right]
\end{aligned}
$$

This equation says that the current borrowing capacity is the value of the project $X_{t}$ minus the present value of future restructuring costs. 
The market value of the $m$-period bond in period $t$ is

$$
\begin{aligned}
D_{t}(m)= & (1-\operatorname{Pr}(m)) \mathbf{E}_{t}\left[e^{-m r} \min \left\{F_{t+m}, X_{t+m}\right\}\right] \\
& +\operatorname{Pr}(m) \mathbf{E}_{t}\left[e^{-m r} \min \left\{F_{t+m}, V_{t+m}-1_{\left\{V_{t+m}<F_{t+m}\right\}} \lambda X_{t+m}\right\}\right] \\
& -1_{\left\{V_{t}(m)<F_{t}\right\}} \lambda X_{t} .
\end{aligned}
$$

This equation says that the bond price is its expected payoff upon maturity minus the current cost of restructuring. If the rollover constraint is satisfied in period $t$, there exists a maturity $m$ and face value $F_{t+m}$ such that $D_{t}(m)=F_{t}$. As rollover risk becomes significant, the face value of bonds must rise so that the firm effectively transfers the equity value of the firm to the bondholders. The face value of maturing bonds $F_{t}$ is an endogenous state variable in that it depends on the history of financing policy.

The value of the firm in period $t$, under the policy of issuing $m$-period bonds, is its borrowing capacity minus the current restructuring cost if rollover fails, that is $V_{t}(m)-$ $1_{\left\{V_{t}(m)<F_{t}\right\}} \lambda X_{t}$. The firm's net worth under this policy is $V_{t}(m)-D_{t}(m)-1_{\left\{V_{t}(m)<F_{t}\right\}} \lambda X_{t}$. If the rollover constraint is satisfied, maximizing the firm's net worth is equivalent to maximizing its borrowing capacity $V_{t}(m)$ subject to the constraint $D_{t}(m)=F_{t}$. (Even if rollover is successful in the current period, the firm's value is less than the value of the project $X_{t}$ because it reflects the present value of future restructuring costs.) If the rollover constraint is not satisfied, the firm must restructure the maturing bonds at market value $D_{t}(m)=V_{t}(m)-\lambda X_{t}$. In this case, maximizing the bondholder's present value is equivalent to maximizing the firm's borrowing capacity $V_{t}(m)$. The choice of optimal maturity, and corresponding face value $F_{t+m}$, leads to the value function

$$
V_{t}=\max _{m \in\{1, \ldots, M\}} V_{t}(m) .
$$

Proposition 1. An optimal financing strategy is to issue: (i) bonds of the shortest maturity as long as subsequent rollover is guaranteed and (ii) bonds of the maximum maturity when 
its net worth is zero and debt restructuring is inevitable.

Proposition 1 characterizes the optimal financing strategy, which we prove in the Appendix. To summarize, an optimal financing strategy of a long-term asset is to initially roll over short-term bonds. In particular, the firm should roll over the one-period bond as long as rollover is guaranteed in the subsequent period. Through short-term financing, the firm can remain flexible and react quickly when the value of its assets falls. The firm should then hedge liquidity risk, that is secure long-term financing, as soon as rollover risk becomes significant. By doing so, the firm delays the realization of inefficient restructuring costs for as long as possible. Our proposition does not fully characterize the transition from one-period bonds to the maximum maturity, which can be accomplished in the continuous-time limit as the time interval between periods shrinks.

\section{Discussion}

\section{A. State-Dependent Maximum Maturity}

Our analysis so far has assumed that the maximum available maturity is constant and independent of the firm's financial health. In reality, the maximum maturity may decline as the firm's financial health worsens. This effect can be captured in reduced form by assuming that the maximum maturity is a declining function of the firm's leverage ratio above some bound (e.g., $M_{t}=M\left(F_{t} / X_{t}\right)$, where $\left.M^{\prime} \leq 0\right)$. As shown in the Appendix, a lower maximum maturity increases the likelihood (or frequency) of debt restructuring prior to the project's maturity, thereby reducing firm value. Therefore, if the maximum maturity is sensitive to changes in the leverage ratio, the firm would like to secure long-term financing at a lower leverage ratio than our previous analysis may have suggested.

The relation between the maximum maturity and the firm's financial health can be endogenized by informational frictions that affect the firm's financing options. These frictions become more important as the firm's financial health worsens because debt becomes more 
sensitive to asymmetric information. More profitable firms may want to signal their creditworthiness by exposing themselves to rollover risk through short-term financing. This makes long-term financing more expensive, even to the point that the less profitable firms choose to pool with the more profitable firms (Flannery 1986; Diamond 1991).

\section{B. Financing with Multiple Maturities and Repurchases}

In our analysis, we have assumed that the firm has only bonds of a single maturity outstanding at any point in time. If the firm can have bonds of multiple maturities outstanding at the same time, richer financing strategies are possible. Returning to the three-period example in Section I, suppose the firm initially issues $\$ 100$ of two-period bonds, and issues an additional $\$ 100$ of two-period bonds if it reaches node (1b). That is, the firm's liabilities at node (1b) consists of $\$ 100$ of bonds with one period until maturity and $\$ 100$ of bonds with two periods until maturity. While this strategy allows the firm to successfully finance the project until maturity, it forces the firm to store cash from node (1b) to period 2. Although storing cash for precautionary reasons can be optimal in some settings (e.g., Holmström and Tirole 2001), our strategy is more efficient if storing cash is costly (e.g., due to agency costs).

The firm can avoid storing extra cash if it is allowed to repurchase its outstanding bonds prior to maturity. At node (1b), the firm can use the $\$ 100$ raised through the issuance of new two-period bonds to retire outstanding bonds that are scheduled to mature in period 2. Consequently, the firm is indifferent between issuing one- or two-period bonds in period 0 once we allow for repurchases. In reality, the repurchase of all outstanding bonds prior to maturity may be impractical since owners of bonds are often dispersed and difficult to locate.

\section{Maturity Risk Shifting due to Government Guarantees}

Our three-period example is also useful for illustrating a form of risk shifting through the suboptimal choice of bond maturity. At node (2c), the value of the project is $\$ 99$, which is 
only $\$ 1$ less than the value necessary to roll over maturing bonds. What is striking about the situation is that a shortfall in financing of a mere $\$ 1$ causes a wealth destruction of $\$ 16$. The government might therefore be tempted to provide a guarantee to the new bondholders at node (2c), insuring a minimum payoff of $\$ 99$ in period 3. Such a guarantee creates a social value of $\$ 16$ by allowing rollover at node (2c), while costing the government $\$ 1$ in expectation.

However, the government guarantee distorts the ex-ante incentives of the firm. The presence of the guarantee prevents the firm from choosing the socially efficient short-long strategy. Knowing that the government guarantee will allow the firm to refinance at node (2c), it is now optimal for the firm to issue the one-period bond at node (1b), or equivalently the two-period bond in period 0. By doing so, the firm triggers a wealth transfer from the government by forcing the government to absorb the downside. 


\section{Appendix}

We prove Proposition 1 in this appendix. We first rescale all variables by $X_{t}$ since the maximization problem is homogeneous in project value. Let $\widehat{V}_{t}=V_{t} / X_{t}-1$ and $\widehat{F}_{t}=$ $F_{t} / X_{t}-1$. To simplify notation, let $r(m)=r-\log \left(X_{t+m} / X_{t}\right) / m$ be the riskless interest rate minus the realized per-period return on the project. Define

$$
\begin{aligned}
\widehat{V}_{t}(m)= & \frac{V_{t}(m)}{X_{t}}-1 \\
= & \operatorname{Pr}(m) \mathbf{E}_{t}\left[e^{-m r(m)}\left(\widehat{V}_{t+m}-1_{\left\{\widehat{V}_{t+m}<\widehat{F}_{t+m}\right\}} \lambda\right)\right] \\
\widehat{D}_{t}(m)= & \frac{D_{t}(m)}{X_{t}}-1 \\
= & (1-\operatorname{Pr}(m)) \mathbf{E}_{t}\left[e^{-m r(m)} \min \left\{\widehat{F}_{t+m}, 0\right\}\right] \\
& +\operatorname{Pr}(m) \mathbf{E}_{t}\left[e^{-m r(m)} \min \left\{\widehat{F}_{t+m}, \widehat{V}_{t+m}-1_{\left\{\widehat{V}_{t+m}<\widehat{F}_{t+m}\right\}} \lambda\right\}\right] \\
& -1_{\left\{\widehat{V}_{t}(m)<\widehat{F}_{t}\right\}} \lambda .
\end{aligned}
$$

The proof for the first part of the proposition follows. Let $k<l \leq M$, where $k$ is a shorter maturity and $l$ is a longer maturity. Assume that rollover is feasible for both bonds in period $t$. In order to compare these strategies, it is useful to introduce a hypothetical third strategy that involves a put option. More specifically, create a European put option in period $t$ that settles on the value $V_{t+k}(l-k)$ in period $t+k$ at the exercise price of $F_{t+k}$. The payoff of the put option is $\max \left\{F_{t+k}-V_{t+k}(l-k), 0\right\}$ in period $t+k$. Now suppose the firm follows a hypothetical strategy of financing through the $k$-period bond and the put option in period $t$. Upon maturity of the bond in period $t+k$, the firm rolls over by issuing

a $(l-k)$-period bond, the feasibility of which is guaranteed through the put option. The value of this hypothetical strategy is

$$
\begin{aligned}
\widehat{V}_{t}(k, l-k) & =\operatorname{Pr}(k) \mathbf{E}_{t}\left[e^{-k r(k)}\left(\widehat{V}_{t+k}(l-k)+\max \left\{\widehat{F}_{t+k}-\widehat{V}_{t+k}(l-k), 0\right\}\right)\right] \\
& =\operatorname{Pr}(k) \mathbf{E}_{t}\left[e^{-k r(k)} \max \left\{\widehat{F}_{t+k}, \widehat{V}_{t+k}(l-k)\right\}\right]
\end{aligned}
$$


We calculate an upper bound on the value of the hypothetical strategy as

$$
\begin{aligned}
\widehat{V}_{t}(k, l-k) & \leq \operatorname{Pr}(k) \mathbf{E}_{t}\left[e^{-k r(k)} \max \left\{\widehat{F}_{t+k}, \max _{m \in\{1, \ldots, M\}} \widehat{V}_{t+k}(m)\right\}\right] \\
& =\operatorname{Pr}(k) \mathbf{E}_{t}\left[e^{-k r(k)} \widehat{V}_{t+k}\right]=\widehat{V}_{t}(k) .
\end{aligned}
$$

The second line follows from the assumption $\widehat{V}_{t+k} \geq \widehat{F}_{t+k}$ that rollover of the $k$-period bond is feasible in period $t+k$. We calculate a lower bound on the value of the hypothetical strategy as

$$
\begin{aligned}
\widehat{V}_{t}(k, l-k) & \geq \operatorname{Pr}(k) \mathbf{E}_{t}\left[e^{-k r(k)} \widehat{V}_{t+k}(l-k)\right] \\
& =\operatorname{Pr}(k) \mathbf{E}_{t}\left[e^{-k r(k)} \operatorname{Pr}(l-k) \mathbf{E}_{t+k}\left[e^{-(l-k) r(l-k)}\left(\widehat{V}_{t+l}-1_{\left\{\widehat{V}_{t+l}<\widehat{F}_{t+l}\right\}} \lambda\right)\right]\right] \\
& =\operatorname{Pr}(l) \mathbf{E}_{t}\left[e^{-l r(l)}\left(\widehat{V}_{t+l}-1_{\left\{\widehat{V}_{t+l}<\widehat{F}_{t+l}\right\}} \lambda\right)\right]=\widehat{V}_{t}(l) .
\end{aligned}
$$

Hence, $\widehat{V}_{t}(k) \geq \widehat{V}_{t}(l)$, which completes the proof for the first part.

To prove the second part of the proposition, suppose the firm has zero net worth in period t. Then both current and subsequent restructuring is inevitable since the face value of bonds must exceed the maximum possible payoff of the project, that is $F_{t+m}=\sup X_{t+m}>V_{t+m}$ for all $m \geq 1$. Therefore, the face value of maturing bonds is no longer a state variable. The choice of optimal maturity must also be independent of the state. The value function is constant and is given by

$$
\begin{aligned}
\widehat{V}(m) & =\operatorname{Pr}(m) \mathbf{E}_{t}\left[e^{-m r(m)}(\widehat{V}(m)-\lambda)\right] \\
& =\frac{-\lambda}{1 / \operatorname{Pr}(m)-1}
\end{aligned}
$$

Note that the value function is increasing in $m$, which completes the proof of the second part. 


\section{References}

Brunnermeier, Markus K. and Lasse Heje Pedersen, "Market Liquidity and Funding Liquidity," Review of Financial Studies, 2009, forthcoming.

- and Martin Oehmke, "The Maturity Rat Race," 2009. Working Paper, Princeton University.

Buchheit, Lee C. and G. Mitu Gulati, "Sovereign Bonds and the Collective Will," Emory Law Journal, 2002, 51 (4), 1318-1363.

Diamond, Douglas W., "Debt Maturity Structure and Liquidity Risk," Quarterly Journal of Economics, 1991, 106 (3), 709-737.

Flannery, Mark J., "Asymmetric Information and Risky Debt Maturity Choice," Journal of Finance, 1986, 41 (1), 19-37.

Holmström, Bengt and Jean Tirole, "Liquidity and Risk Management," Journal of Money Credit and Banking, 2000, 32 (3), 295-319.

_ and _ , "LAPM: A Liquidity-Based Asset Pricing Model," Journal of Finance, 2001, 56 (5), 1837-1867.

Myers, Stewart C., "Determinants of Corporate Borrowing," Journal of Financial Economics, 1977, 5 (2), 147-175.

Vasicek, Oldrich, "An Equilibrium Characterization of the Term Structure," Journal of Financial Economics, 1977, 5 (2), 177-188. 